\title{
A PEdagogia do AXé: PROMOÇÃO dA CIDAdANIA E FORTALECIMENTO DA IDENTIDADE NEGRA PELO PROJETO ABC MUSICAL ${ }^{1}$
}

\author{
Luiza Sousa de Carvalho ${ }^{2}$ \\ DOI: $10.26512 /$ revistacalundu.v3i1.25236
}

\section{Resumo}

A tradição oral é uma herança africana que atravessa a cultura afro-brasileira e se traduz numa estratégia para a manutenção dos saberes tradicionais no Brasil, e também para o ensinamento de saberes diversos. A evidência de uma Pedagogia do Axé viabilizou o Projeto $\mathrm{ABC}$ musical que, por meio do ensino de música, com foco em ritmos afro-brasileiros, tem atuado diretamente no fortalecimento da identidade negra e na promoção de cidadania de crianças e adolescentes, bem como de seus familiares, e da comunidade do Jardim ABC, Cidade Ocidental - GO. O resgate fundamental deste texto é destacar e valorizar as ações do Ilê Axé T’OjuLabá (comunidade de matriz africana), que enfrentam o racismo e a realidade da vulnerabilidade social no contexto da sociedade brasileira.

Palavras-chave: Cidadania; Cultura Afro-brasileira; Ensino Musical; Identidade Negra; Candomblé.

\section{LA PEDAGOGÍA DEL AXÉ: PROMOCIÓN DE LA CIUDADANÍA Y FORTALECIMIENTO DE LA IDENTIDAD NEGRA POR EL PROYECTO ABC MUSICAL}

\begin{abstract}
Resumen
La tradición oral es una herencia africana que atraviesa la cultura afro-brasileña y se traduce en una estrategia para el mantenimiento de los saberes tradicionales en Brasil, y también para la enseñanza de diversos saberes. La evidencia de una pedagogía del Axé viabilizo el proyecto $\mathrm{ABC}$ musical que, por medio de la enseñanza de música, con foco en ritmos afro-brasileño, ha actuado directamente en el fortalecimiento de la identidad negra y en la promoción de la ciudadanía de niños y adolescentes, así como de sus familiares, y de la comunidad del Jardín ABC, Ciudad Occidental - GO. El rescate fundamental de este texto es destacar y valorar las acciones de Ilê Axé T'OjuLabá
\end{abstract}

\footnotetext{
${ }^{1} \mathrm{O}$ presente artigo resulta de um esforço coletivo em traduzir para a linguagem formal e acadêmica as práticas desenvolvidas no Ilê Axé T'OjuLabá, portanto referencio aos mais velhos e mais velhas, irmãs e irmãos e em especial minha Iyá Mãe Dora TyOyá.

${ }^{2}$ Assistente Social graduada pela Universidade de Brasília e mestranda em Política Social (PPGPS) pela mesma universidade. Integra o Núcleo de Estudos e Pesquisas em Política Social (CEAM/UnB). Ekedji Ty Oyá do Ilê Axé T’OjuLabá. E-mail: carvalholuiza@live.com.
} 
(comunidad de matriz africana), que enfrenta el racismo y la realidad de la vulnerabilidad social en el contexto de la sociedad brasileña.

Palabras clave: Ciudadanía; Cultura Afro-brasileña; Enseñanza Musical; Identidad Negra; Candomblé.

"Nossos ancestrais vieram sem nada nas mãos, com a roupa do corpo. Trouxeram toda sabedoria nas cabeças, transmitida pela vivência e pela fala. Candomblé é manter essa tradição viva" (Mãe Dora TyOyá).

\section{De onde vem...}

Olorun, o princípio de tudo. Que vive e dá a vida ao Orun, que rege as forças dos Orixás. Estes, que nos cuidam, nos protegem e nos guiam nas missões no Aiê. Os Orixás nos transmitem o Axé: força que assegura a existência, o princípio vital. O Axé é encontrado na presença e na existência dos Orixás, que são, pois, as forças da natureza e suas manifestações. Exú é um transmissor de axé, ele é a comunicação, a conexão entre o Orun e o Aiê. A ele referenciamos nossos caminhos e também nossa individualidade, nossa fé. Mojubá Exú, Laroiyê Exú.

O Candomblé, religião afro-brasileira de matriz africana, ou a "religião negra", é para Helena Teodoro Lopes um processo cultural e "fonte de um ethos, indicadora de comportamentos, hábitos, enfim, de uma maneira negra de ser" que:

Estabelecendo e proporcionando uma ética própria, vem imprimindo formas de relações sociais, estipulando formas próprias de organização e hierarquias, estimulando a vida comunal e estabelecendo padrões estéticos próprios e formas específicas de comunicação e acesso ao riquíssimo sistema simbólico pleno de conhecimento e sabedoria que vai caracterizar uma pedagogia negra iniciática (LOPES, 1987, p 64).

Ou seja, o Candomblé está inserido em outros marcos civilizatórios que não a perspectiva colonial presente no Brasil. Dessa forma, ele viabiliza a condução de uma ética que em nada corresponde à colonial. Por sua vez, é o oposto, principalmente em se tratando de estética, simbologias, cosmologia, saberes, hierarquias e, sobretudo o modo de transmitir conhecimento, que aqui chamaremos de Pedagogia do Axé.

Os modos, os ofícios, os saberes e os fazeres dos povos sequestrados de África e trazidos para o Brasil, foram e continuam sendo mantidos por algumas estratégias ligadas a tradição oral que atravessa nossa vivência. No Candomblé pouco se escreve, a 
tradição oral é também ligada a um preceito muito importante da cosmologia vind'Africa: respeito aos mais velhos. O que pode ter uma correspondência com a hierarquia no ocidente, mas não é uma relação de dominação. É, sobretudo, o respeito à sabedoria ancestral, daqueles que vieram antes de nós, mais viveram que nós, que possuem a experiência, e, portanto, o dever de ensinar aos mais novos por meio da tradição oral.

Para o filósofo africano Amadou Hampaté Bá, a tradição oral é a "herança de conhecimentos de toda espécie, pacientemente transmitidos de boca a ouvido, de mestre a discípulo, ao longo dos séculos" por aqueles que são, segundo ele a "memória viva" da África (HAMPATÉ BÁ, 2010, p. 167). Assim aprendemos com a oralidade do cotidiano no Ilê, e reconhecemos a viva memória de África, transmitida por nossas/os mais velhas/os. O ponto central desse processo é que, de acordo com o autor, o espiritual e o material não são opostos, e não se dissociam. A tradição oral "conduz o homem a sua totalidade", compõe e é composta por "religião, conhecimento, ciência natural, iniciação e arte, história, divertimento e recreação". Tudo isso contribui para uma ontologia africana, e, portanto, uma ontologia negra: "síntese de tudo o que existe, receptáculo por excelência da Força suprema e confluência de todas as forças existentes" (HAMPATÉ BÁ, 2010, p. 171).

$\mathrm{O}$ autor infere acerca da resistência [ocidental] em atribuir confiança à oralidade em relação à escrita, e então questiona: "Não faz a oralidade nascer a escrita?" e retoma a importância moral da palavra.

Lá onde não existe a escrita, o homem está ligado à palavra que profere. Está comprometido por ela. Ele é a palavra, e a palavra encerra um testemunho daquilo que ele é. A própria coesão da sociedade repousa no valor e no respeito pela palavra (HAMPATÉ BÁ, 2010, p. 168).

Dessa forma a fala que vai e que tem seu retorno, [escuta], cria "movimento e ritmo, e, portanto, vida e ação", onde a tradição oral, pois confere a palavra "a dupla função de conservar e destruir" (Idem, p. 172).

Se restarem dúvidas acerca da importância dessa tradição e principalmente sobre a capacidade de transmitir os saberes e preservar a cultura afro-brasileira é simples: desde o século XVI até o século XIX houve a presença de povos africanos escravizados no Brasil de maneira violenta. Após a escravatura, além da proibição da entrada destes povos, também foram determinadas várias legislaturas que criminalizavam as práticas 
culturais negras como é o caso da capoeira, dos maracatus, do samba, das religiões negras e o pito do pango [como era chamada a maconha], dentre outras. Ainda assim, a capoeira é bastante presente na contemporaneidade, o samba [e sua diversidade] é o ritmo mais expressivo da cultura brasileira e apesar do aumento recente dos ataques aos templos de matriz africana e do racismo religioso, as religiões negras têm se mostrado ainda mais resistentes e preservam seus cultos desde os Calundus. São tempos difíceis, mas já houve tempos piores. A resistência faz parte de tudo que descende da matriz civilizatória africana, sobretudo nos países atlânticos que carregam a marca da escravização dos corpos negros, da subalternização dos saberes africanos e da negação da relação colonial como pressuposto para a construção de uma nova sociedade. Contudo, em quase nada essas "novas composições societárias" rompem com os pactos coloniais, que reverberam na autonomia e no enfraquecimento da identidade negra das populações amefricanas ${ }^{3}$.

O epistemicídio denunciado por Sueli Carneiro como essa agência branca que anula os conhecimentos dos povos subalternizados inicia justamente com a deturpação e desvalorização da tradição oral, em relação à tradição escrita moderna (CARNEIRO, 2005). Assim, se nem sequer a forma de pensar e produzir conhecimento dos povos africanos são valorizadas, o que se fala e como fala, é ainda mais desqualificado. Esses processos refletem nas mortes evidentes e nas mortes simbólicas da população afrodescendente em todos os territórios afrodiaspóricos.

Não se pode negar a violência desse processo, sobretudo em se tratando da visibilidade positiva que a cultura afro-brasileira tem ao redor do mundo, mas que não referencia, tampouco incentiva que as raízes dessas expressões sejam preservadas, valorizadas e propagadas. O julgamento de que os povos sem escrita não possuíam cultura reflete na educação moderna e no processo de aculturação pelo qual temos passado desde a colonização (HAMPATÉ BÁ, 2010).

A educação acultural, acrítica e valorizada como ciência neutra é mais um dos reflexos do racismo, uma vez que a universalidade do pensamento europeu impera de maneira silenciosa em todas as teorias do conhecimento. Mesmo com a construção da Lei 10.639, e posteriormente da Lei 10.645 que falam do ensino das culturas afrobrasileiras e indígenas, o que se ensina acerca da história real da construção do Brasil enquanto país e enquanto povo é insatisfatório e promove a desvinculação com o

\footnotetext{
${ }^{3}$ Para Lélia González, América Africana ou Améfrica Ladina (GONZALEZ, 1984).
} 
passado e a [des]construção do presente. Essa ruptura tem se apresentado como uma fonte de distanciamento daquilo que se é daquilo que se pode ser e, além do impacto na identidade, têm sido ainda mais violentos os impactos na saúde e na preservação dos modos de vida da população negra.

O acaso serve aos outros. Quanto a mim, acredito no axé... hoje acordei com a música Massemba interpretada por Maria Bethânia ${ }^{4}$ e também por Virgínia Rodrigues, e composta por Roberto Mendes e Capinam, que diz: "Que noite mais funda calunga, no porão de um navio negreiro. Que viagem mais longa candonga ouvindo o batuque das ondas, compasso de um coração de pássaro no fundo do cativeiro. É o semba do mundo calunga batendo samba em meu peito”. A referência à travessia do Atlântico encontra dor e sofrimento, mas também o compasso do semba, ritmo de umbigada de origem quimbundo, e que acreditamos que trouxe influências para a gênese do samba de roda e por aí em diante, influenciando também outras brincadeiras de roda e expressões afrobrasileiras como jongo, coco, etc. De acordo com Nei Lopes, o Samba é um

Nome genérico de várias antigas danças brasileiras de origem africana e da música que acompanha cada uma dessas danças. Modernamente o nome samba designa a expressão musical multiforme que constitui a espinha dorsal e a corrente principal da música popular brasileira. De incontestável origem banta, o termo foi, outrora, usado também no Prata, nas formas samba e semba, para designar o folguedo mais comumente conhecido como cambombe (LOPES, 2006, p.151).

Essa ligação não é uma simples influência, como tantas outras de origens diversas. O elo entre o samba e o semba resulta de estratégias de sobrevivência, de aguentar viver sob as condições impostas pelos colonizadores, sob o açoite dos feitores, sob a fome. É sobre a saudade, sobre o Banzo:

Espécie de melancolia ou nostalgia com depressão profunda, quase sempre fatal, em que caíam alguns africanos escravizados nas Américas. O termo tem origem ou no quicongo mbanzu, "pensamento", "lembrança", ou no quimbundo mbonzo, "saudade", "paixão", "mágoa" (LOPES, 2006, p. 27).

Esse Banzo hoje pode ser encontrado naquilo que Vilma Piedade denomina por Dororidade. Contêm as dores, as sombras, o vazio, a ausência, a fala silenciada, a dor causada pelo racismo. Essa dor é preta. A dororidade é aquilo que nos conecta, que nos

\footnotetext{
${ }^{4}$ Disponível em: https://www.youtube.com/watch?v=sfGMCm-ZPfQ.
} 
permite fortalecermo-nos pelo encontro da dor. Resistimos e resistiremos, mas também lutamos por uma vida além da resistência (PIEDADE, 2017).

\section{O Projeto ABC Musical}

Foi pensando na importância da resistência da tradição oral e de todas as tradições afro-brasileiras, bem como nas necessidades da comunidade próxima, que Mãe Dora TyOyá, Iyalorixá do Ilê Axé T'OjuLabá, idealizou e fez nascer o Projeto ABC Musical, com o auxílio de seus filhos de santo e de outras parcerias. A Associação Religiosa e Cultural Quilombo T'OjuLabá, hoje certificada como Ponto de Cultura do DF, promove desde 2014 o Projeto ABC Musical, que atende crianças e adolescentes de 3 a 17 anos da comunidade próxima ao terreiro, principalmente da região do Jardim ABC, bairro da Cidade Ocidental - GO, município que compõe a RIDE. O terreiro está situado na divisa entre as Regiões Administrativas do DF: Santa Maria e São Sebastião, e também com o Estado de Goiás, pela proximidade com o Jardim ABC. Essa comunidade fica a $45 \mathrm{~km}$ de distância de Brasília, $20 \mathrm{~km}$ do centro da Cidade Ocidental e a $10 \mathrm{~km}$ do Quilombo do Mesquita. São mais de 15 mil habitantes que moram na região, um bairro que enfrenta grandes dificuldades, pois a situação de divisa lhe confere a ausência de serviços, como saneamento básico, energia elétrica, asfalto e principalmente segurança pública. Além disso, as escolas não têm capacidade de atender todas as demandas, o que faz com que busquem ensino no DF, e então a distância é o maior desafio, uma vez que o transporte escolar também não é suficiente e o transporte público do "entorno" precário. Todos esses fatores limitam bastante o acesso à educação, além do fato da vulnerabilidade latente, um indicador presente nas composições familiares, e na comunidade como um todo, que repercute na entrada precoce no mundo do trabalho, promovendo um desgaste escolar e dificuldade de conclusão dos estudos por grande parte dos jovens do Jardim ABC.

Muitas crianças já passaram pelo projeto e hoje são cerca de 15 , com uma faixa etária bastante diversa. Além do ensino de música promovemos um contato mais direto com a cultura afro-brasileira e incentivamos a música como lazer e também como possibilidade de trabalho. Percebemos que a iniciação musical tem cada vez mais atuado no fortalecimento da identidade e, sobretudo na autoestima, tanto das crianças como das famílias, que enxergam outras possibilidades de futuro a partir da música. 
Compõem o quadro de professores: Amílcar Paré, Lucas de Campos, José Carlos e Wellington Nascimento. Para a operacionalização muitas outras pessoas participam, pois o projeto também oferece apoio pedagógico, transporte e alimentação, dentre outras atividades. Periodicamente promovemos oficinas com mestras/es de outros ritmos, artes plásticas, teatro, atividades externas, lazer etc. Além disso, as crianças já fizeram apresentações em eventos, tanto o grupo, como alguns adolescentes fizeram participações. Hoje além das aulas do projeto, alguns adolescentes compõem na condição de percussionistas o grupo Afoxé Ogum Pá que é formado pela comunidade do Ilê Axé T’OjuLabá. A relação delas/es com a música já ultrapassou a condição de aprendizes e esse é um resultado do trabalho coletivo e da importância da pedagogia trabalhada no projeto.

\section{A Pedagogia do Axé}

As particularidades estabelecidas no interior de um terreiro de Candomblé são múltiplas, a se considerar a composição de outros marcos civilizatórios que não os coloniais e ocidentais, como a cosmovisão afro-pindorâmica ${ }^{5}$. Uma delas é a importância da roda, do círculo, da circularidade, que pode permitir uma melhor biointeração, ou seja, uma produção consciente, um resultado coletivo, onde os saberes se entrelaçam do mais velho ao mais novo, sem distinções ou hierarquias, sem relações de opressão e dominação, ou de maneira a minimizar os efeitos exteriores dessas condições estruturais.

Através da tradição oral, dos ensinamentos por meio da fala, consideramos que, a partir do ensino de música, outros conhecimentos e informações são partilhadas como a certeza de que "só é feliz quem realmente sabe que a África não é um país, esquece o que o livro diz, ele mente, ligue a pele preta a um riso contente" ${ }^{6}$. A imagem de uma África submissa ao continente europeu, de africanos negros em situação de miséria e fome, e que subsistem às ajudas humanitárias é um desfavor e uma inverdade. Apesar de todos os esforços coloniais e exploratórios, mesmo se considerando a violência de todos esses processos nos dias atuais, a África não é uma só, e muito menos impera apenas o sofrimento. O continente africano é um somatório de culturas diversas, das quais alguns povos foram sequestrados e mantidos em cativeiros em colônias europeias

\footnotetext{
5 Categoria de Antônio Bispo para denominar os povos nativos e escravizados no Brasil, união de Pidorâmicos com Africanos.

${ }^{6}$ Letra da música Mufete - Emicida, do álbum Sobre Crianças, Quadris, Pesadelos e Lições de Casa... disponível em: https://www.youtube.com/watch?v=zypOpcW62T8.
} 
na América. Esse processo condicionou dor e sofrimento, mas também estratégias da manutenção da vida e dos saberes. Portanto aqui faremos um dialogo com a musicalidade africana. Retomo a contribuição de Hampaté Bá que diz:

Para que a fala produza um efeito total, as palavras devem ser entoadas ritmicamente, por que o movimento precisa de ritmo, estando ele próprio fundamentado no segredo dos números. A fala deve reproduzir o vaivém que é a essência do ritmo.

Nas canções rituais e nas fórmulas encantatórias, a fala é, portanto, a materialização da cadência (HAMPATÉ BÁ, p. 174).

Assim sendo, a musicalidade compõe a fala e por ela é composta. A relação está na potencialidade da fala, do retorno e, por consequência, dos efeitos, do ritmo, do movimento e do fundamento. A cadência mobiliza capacidades e inteligências outras, dessa forma, os ensinamentos tendem a se fixarem não apenas aos hábitos, mas aos modos de ser e à construção de formas de ser que corresponda a quem se é, e não ao ser outro, em relação ao colonizador (CARNEIRO, 2005; FANON, 1979).

Paulo Freire, em seus ensinamentos acerca da pedagogia, nos traz a importância do reconhecimento e a assunção da identidade cultural na prática do ensino, ele retoma a relevância daquilo que se assume como também a ação de assumir. Para ele, essa é uma tarefa da prática educativo-criativa:

propiciar condições em que os educandos em suas relações uns com os outros e todos com o professor ou a professora ensaiam a experiência profunda de assumir-se. Assumir-se como ser social e histórico, como ser pensante, comunicante, transformador, criador, realizador de sonhos, capaz de ter raiva por que capaz de amar. Assumir-se como sujeito por que capaz de reconhecer-se como objeto (FREIRE, 2011, p. 42).

Dessa forma, o ensino pautado na prática da assunção, trabalha a identidade: tanto o reconhecimento e o fortalecimento, porque auxilia no descobrimento de quem se é, e de como dali em diante essa assunção reflete nas escolhas, decisões, e relações internas e externas dos educandos. Um fator importante desse processo é que "a assunção de nós mesmos não significa a exclusão dos outros. É a "outredade" do "não eu", ou do tu, que me faz assumir a radicalidade de meu eu" (FREIRE, 2011, p. 42). Dessa forma, a identidade afro-brasileira da maioria das crianças e adolescentes do Projeto $\mathrm{ABC}$ Musical não deve ser menosprezada, mas, sobretudo, evidenciada e trabalhada, pois, segundo Freire: 
A experiência histórica, política, e social dos homens e das mulheres jamais pode se dar "virgem" do conflito entre as forças que obstaculizam a busca da assunção de si por parte dos indivíduos e dos grupos e das forças que trabalham em favor daquela assunção" (Idem, p. 42).

A partir desse diálogo com Freire, inferimos que a pedagogia em si possibilita uma educação formadora e transformadora, que rompa com os pressupostos do pragmatismo e do autoritarismo no exercício de ensinar. A pedagogia do axé, por sua vez, potencializa essa dinâmica, por meio das capacidades metodológicas que se ligam à construção do ser a partir daquilo que se é como já foi mencionado, a partir da ancestralidade e de tudo que forma o ser afrodiásporico, não apenas como uma qualidade, mas em que pese a centralidade desse processo na construção identitária e social.

Da mesma forma em que na tradição oral os ensinamentos não são apenas um repasse do conhecimento, mas uma cadeia de valorização da ancestralidade, dos preceitos e da matriz ontológica e civilizatória africana, para Paulo Freire, ensinar não é transferir conhecimento, mas é "criar as possibilidades para a sua própria produção ou a sua construção". Dessa forma, encontramos novamente a importância da tradição oral no processo de ensinar, com o valor da palavra, por ser toda a verdade que forma o ser e que, assim, pode contribuir na formação de outros seres.

Considerando o ensino de música, com ênfase nos ritmos e brincadeiras afrobrasileiras, por meio da pedagogia do axé, que é constituída por outros ambientes, por outras metodologias e por sua vez, pela busca e pela prática da liberdade coletiva, encontramos também em Paulo Freire a exigência da alegria e esperança como prática pedagógica. Para ele "a esperança faz parte da natureza humana”, e

\footnotetext{
É um condimento indispensável à experiência histórica. Sem ela, não haveria história, mas puro determinismo. Só há história onde há tempo problematizado e não pré-dado. A inexorabilidade do futuro é a negação da história (FREIRE, 2011, p.71).
}

Essa esperança, da qual Freire trata, é vontade, ação, é a crença na mudança. Não apenas por meio da superação do presente, mas justamente pela problematização do presente, pela ação para a construção do futuro é que compreendemos a Educação como prática libertadora. Ele completa: 
Não posso, por isso, cruzar os braços fatalistamente diante da miséria, esvaziando, desta maneira, minha responsabilidade no discurso cínico e "morno", que fala da impossibilidade de mudar por que a realidade é mesmo assim. O discurso da acomodação ou de sua defesa, o discurso da exaltação do silêncio imposto de que resulta a imobilidade dos silenciados, o discurso negador da humanização de cuja responsabilidade não podemos nos eximir. A adaptação a situações negadoras de humanização só pode ser aceita como consequência da experiência dominadora, ou como exercício de resistência, como tática na luta política (FREIRE, 2011, p. 74).

Por isso a importância da centralidade dos sujeitos na promoção de uma pedagogia do axé, que olhe para o passado e aprenda com o que já foi. Olhe para o presente com esperança, e, sobretudo, com a responsabilidade de não acomodação, não aceitação, e permeada pelo ímpeto da humanização [a condição extraída dos sujeitos negros quando da justificativa de escravização], e ressignifique o ser, o fazer, o ensinar. Que seja capaz de promover transgressões, contra fronteiras e distâncias, e que promova liberdade (HOOKS, 2013, p. 24).

A liberdade é um horizonte importante, contudo, anterior a ela, precisamos considerar as condições de humanidade e cidadania de sujeitos negros [pretos e pardos] no Brasil, e construir o fortalecimento dessa identidade. A pedagogia do axé atua diretamente neste ponto, pois esta reconhece no passado as premissas do presente e invoca ancestralidade para não se resignar às relações de dominação, mas para enfrentálas com a sabedoria daqueles que, há pelo menos 500 anos, resistem aos grilhões da escravatura. Tais afirmativas estão diretamente ligadas com a problematização feita pela professora Marcia Eurico:

A alta concentração da população na categoria parda, quando se analisam pretos e pardos, revela o longo caminho a ser trilhado rumo à consciência do pertencimento étnico-racial, reduzindo as barreiras da cor, pois há, entre os brasileiros, uma falsa ideia de que preta é uma categoria pejorativa - leia-se: feia. Então, uma parcela significativa da população negra vive um doloroso dilema: valorizar a herança africana, ao mesmo tempo em que anseia por determinado status social obtido pela aproximação do grupo racial branco e pela negação da sua própria negritude (EURICO, 2018, p. 526).

Encontramos essa dualidade apontada até mesmo nas crianças. Afinal, quem gosta de ser criticado, excluído, apontado, desacreditado, alvo de deboches e brincadeiras sem graça? Ninguém. A promoção da desvinculação com a negritude está para a população negra de pele clara, desde que se nasce com as especulações sobre as 
possibilidades de clareamento. Contudo, a desvalorização das heranças africanas, não somente fenotípicas, mas religiosas, culturais e éticas é tão latente que atinge a todas as pessoas negras. O objetivo é claro: embranquecimento da população. Seja dos corpos, como dos pensamentos. O racismo assola a nossa sociedade desde sempre, e para a população pobre, em tempos de crise, isso significa ainda mais vulnerabilidade.

É a partir das convicções do presente que Paulo Freire também indica a importância da convicção de que a mudança é possível no exercício do ensinar. Para ele

O mundo não é. O mundo está sendo. Como subjetividade curiosa, inteligente, interferidora na objetividade com que dialeticamente me relaciono, meu papel no mundo não é só o de quem constata o que ocorre, mas também o de quem intervém como sujeito de ocorrências. Não sou apenas objeto da história, mas seu sujeito igualmente (FREIRE, 2011, p. 76).

Ainda que sujeitos de uma resistência que teima em nos inferiorizar, subalternizar e matar, em que

No fundo, as resistências - a orgânica e/ou a cultural - são manhas necessárias à sobrevivência física e cultural dos oprimidos. O sincretismo religioso afro-brasileiro expressa a resistência ou a manha com que a cultura africana escrava se defendia do poder hegemônico do colonizador branco (FREIRE, 2011, p. 76).

Ou seja, a pedagogia do axé se mostra também estratégia de resistência, sobrevivência e movimento entre o passado e o futuro, considerando tanto aquilo que constrói, como aquilo que destrói.

É preciso, porém, que tenhamos na resistência que nos preserva vivos, na compreensão do futuro como problema e na vocação para o Ser Mais como expressão da natureza humana em processo de estar sendo, fundamentos para a nossa rebeldia e não para a nossa resignação em face das ofensas que nos destroem o ser. Não é na resignação, mas na rebeldia em face das injustiças que nos afirmamos (FREIRE, 2011, p. 76).

A pedagogia do axé é o encontro da força vital que precede a fala e que, por meio da tradição oral, presente na cultura vind'Africa, resiste à colonização, promove a continuidade da vida, dos saberes, dos fazeres, do conhecimento, e da ontologia do ser [negro] amefricano, e que, portanto, tem nas suas capacidades a pretensão da liberdade. A essa pedagogia, encontrada no interior das comunidades negras, de matriz africana, dentre outras denominações, depositamos nossa crença, nossa vivência, nossas práticas e assim resistimos. 


\section{Considerações Finais}

A travessia do atlântico trouxe consigo muito mais que cativos. Trouxe povos empossados de conhecimento, de ontologias próprias, e de cosmovisões outras. A capacidade do Orí de guardar e proteger tais riquezas de toda violência colonial é o que nos forma enquanto filhos da diáspora africana, povos afro-pindorâmicos, afrodescendentes/afro-brasileiros e pessoas negras (NASCIMENTO; RATS, 2006).

De tudo que trouxemos às terras pindorâmicas, tenho certeza de que nossas tradições não são apenas modos antigos de perceber e conhecer o mundo, mas principalmente tudo que se manteve em movimento (PIEDADE, 2017). Tal movimento, assim como as ondas do mar atlântico que para cá nos trouxeram, também nos permite voltar. Não fisicamente ao que já foi, mas reconstruir o que nos foi roubado, reconstruir nossos corpos e pensamentos colonizados. A pedagogia do axé é contra colonial. Não apenas por promover rupturas com as formas colonizadas de ensinar, como também por construir estratégias de resistir ao tempo, ao racismo e à própria colonização.

Sem pretensões de concluir o pensamento ou esgotar o assunto, agradeço pela oportunidade de compartilhar um pouco das inquietações e interlocuções que me trouxeram até aqui. Não sou grande estudiosa da pedagogia, mas tenho feito do exercício de ensinar um processo coletivo. Acredito na pedagogia do axé, nas capacidades e confluências da tradição oral, e principalmente nas missões que somos direcionados no Aiê. A pedagogia do axé é Sankofa, é significar o presente e construir o

futuro, sem nunca esquecer do passado, do que já foi feito, de tudo que veio antes. É a inteligência de aprender com os ancestrais, a eles referenciar, por que o caminho se faz ao caminhar.

\section{Referências Bibliográficas}

CAMPOS, Lucas Sousa de (Org). Nosso livro de Samba. Brasília: FAP-DF, 2017.

CARNEIRO, Sueli. A construção do outro como não-ser como fundamento do ser. São Paulo, USP, 2005. (p.96-126). 
EURICO, Márcia Campos. "A luta contra as explorações/opressões, o debate étnicoracial e o trabalho do assistente social". Serviço Social \& Sociedade, São Paulo, n. 133, p. 515-529, dez. 2018.

FANON, Frantz. Os condenados da terra. Rio de Janeiro: Civilização Brasileira, 1979. (Da violência, p. 25-75).

FREIRE, Paulo. Pedagogia da autonomia: saberes necessários à prática educativa. São Paulo: Paz e Terra, 2011.

GONZALEZ, Lélia. "Racismo e Sexismo na Cultura Brasileira". Revista Ciências Sociais Hoje, Anpocs, 1984, p. 223-244.

HAMPATÉ BÂ, Amadou. “A tradição viva”. In: KI-ZERBO (Editor). História geral da África, I: Metodologia e pré-história da África. Brasília: UNESCO, 2010.

HOOKS, Bell. Ensinando a transgredir: A educação como prática da liberdade. São Paulo: Editora WMF Martins Fontes, 2013. (Introdução, p. 9-24).

LOPES, Helena Teodoro (Org.); NASCIMENTO, Maria Beatriz; SIQUEIRA, José Jorge. Negro e Cultura no Brasil - Pequena Enciclopédia da Cultura Brasileira. Rio de Janeiro: UNIBRADE/UNESCO, 1987.

LOPES, Nei. Dicionário escolar afro-brasileiro. São Paulo: Selo Negro Edições, 2006.

NASCIMENTO, Beatriz; RATZ, Alex. “Corpo/mapa de um país longínquo”. In: Eu sou Atlântica, sobre a trajetória de vida de Beatriz Nascimento. São Paulo: Instituto Kwanza e Imprensa Oficial, 2006. (p. 61-69).

PIEDADE, Vilma. Dororidade. São Paulo: Editora Nós, 2017.

PRANDI, Reginaldo. Contos e lendas afro-brasileiras: a criação do mundo. São Paulo: Companhia das Letras, 2007. 
Revista Calundu - Vol.3, N.1, Jan-Jun 2019

SANTOS, Antônio Bispo dos. Colonização, Quilombos: Modos e Significados. Brasília: INCTI, 2015.

Recebido em: 05/05/2019

Aceito em: 13/05/2019 